\title{
A PERCEPÇÃO DAS PESSOAS IDOSAS SOBRE ACESSIBILIDADE NO MUNICÍPIO DE VIÇOSA - MG
}

Beatriz Passos Soares, Simone Caldas Tavares Mafra, Emília Pio da Silva. A percepção das pessoas idosas sobre acessibilidade no município de Viçosa-MG. Revista Saúde Dinâmica, vol. 2, núm.4, 2020. Faculdade Dinâmica do Vale do Piranga. 


\title{
A percepção das pessoas idosas sobre acessibilidade no município de Viçosa-MG
}

\section{The perception of elderly people about acessibility in the municipality of Viçosa - MG}

\author{
Beatriz Passos Soares ${ }^{1 *}$, Simone Caldas Tavares Mafra ${ }^{2}$, Emília Pio da Silva ${ }^{3}$ \\ ${ }^{I}$ Pós-Graduanda, Ciências da Reabilitação, Centro Universitário de Viçosa (UNIVIÇOSA), Viçosa, Brasil, ORCID: \\ https://orcid.org/0000-0002-0661-0382 \\ ${ }^{2}$ Professora titular, Programa de Pós-Graduação em Economia Doméstica, Universidade Federal de Viçosa, Viçosa, \\ Brasil, ORCID: https://orcid.org/0000-0003-2247-2327 \\ ${ }^{3}$ Professora, Curso de Fisioterapia, Faculdade Dinâmica do Vale do Piranga, Ponte Nova, Brasil, \\ https://orcid.org/0000-0001-8130-5196 \\ Autor correspondente: beatrizp.87@yahoo.com
}

\section{Resumo}

A acessibilidade urbana tem se tornando um problema para as pessoas idosas, contribuindo cada vez mais para o isolamento social dessa população. A partir desse cenário, este estudo objetivou descrever a percepção dos idosos sobre a acessibilidade na cidade de Viçosa MG. Trata-se de uma pesquisa qualitativa, de caráter descritivo, para qual foi utilizada a técnica brainstorming (tempestade de ideias). O estudo contou com a participação de 16 idosos, integrantes do Programa Municipal da Terceira Idade (PMTI). Os resultados evidenciaram que os entraves na acessibilidade vão desde a precariedade na infraestrutura da cidade e no transporte público, como a dificuldade para acesso à carteirinha do idoso, até a elementos como a falta de informações, a negligência do Poder Público e mesmo o preconceito dos funcionários dos ônibus. Além das dificuldades, os idosos apresentaram ideias para minimizar estes entraves na acessibilidade, destacando treinamento para os funcionários dos ônibus e a participação dos poderes executivo e legislativo no cumprimento das leis. Por fim, foi possível concluir que em Viçosa, Minas Gerais, a acessibilidade urbana é um problema para as pessoas idosas, afetando sua locomoção.

Palavras-chave: Senilidade; Limitação da mobilidade; Preconceito.

\begin{abstract}
Urban accessibility has become a problem for older people, increasingly contributing to the social isolation of this population. Objective: From this scenario, this study aimed to describe the perception of the elderly about accessibility in the city of Viçosa - MG. Materials and methods: This is a qualitative, descriptive research for which the brainstorming technique was used. The study was attended by 16 seniors, members of the Municipal Old Age Program (PMTI). Results: The results showed that the obstacles to accessibility range from precariousness in the city's infrastructure and public transportation, such as the difficulty of access to the elderly card, to elements such as lack of information, the neglect of the government and even the prejudice of the elderly. bus staff. In addition to the difficulties, the elderly presented ideas to minimize these barriers to accessibility, highlighting training for bus staff and the participation of executive and legislative powers in complying with the laws. Conclusion: Finally, it was possible to conclude that in Viçosa, Minas Gerais, urban accessibility is a problem for the elderly, affecting their mobility.

Key words: Aging; Mobility Limitation; Prejudice.
\end{abstract}




\section{INTRODUÇÃO}

O Brasil, assim como outros países da América Latina, é um país “envelhecido”. A cada ano cresce o número de pessoas idosas em todo mundo. No Brasil o número de pessoas idosas ultrapassa 28 milhões, e até o ano de 2042 essa população chegará a 38,5 milhões de pessoas (17,4\%) (IBGE 2018). Contudo, o país não está preparado para atender às demandas da população idosa, que requer condições especiais, principalmente nas áreas de saúde, acessibilidade dentre outros direitos sociais (SILVA et al. 2018). Corroborando estes princípios, Miranda, Mendes e Silva (2016) enfatizaram que o fenômeno do envelhecimento exige melhorias nas políticas públicas, a fim de proporcionar às pessoas idosas uma vida mais independente, com condições sociais e econômicas favoráveis.

Freire Junior et al. (2013, p. 542) afirmaram que, para se ter um envelhecimento saudável, é preciso uma "interação harmoniosa com o ambiente", sendo importante entendermos que vivemos em constante transformação, e que esta causa grande impacto na adaptação das pessoas idosas na sociedade. Para Micheletto (2011), a comunidade idosa necessita realizar suas atividades de forma independente e participativa, seja em ações sociais, culturais ou familiares. Contudo, esta participação pode se tornar restrita em decorrência de um envelhecimento marcado por doenças, dependência funcional e perda da independência e autonomia. Esse contexto gera impactos negativos no cotidiano do idoso, dentre os quais destacam-se as dificuldades de acessibilidade, que constituem uma barreira à independência física.

As barreiras arquitetônicas e o trânsito mal organizado tornam os idosos pedestres um grupo de maior vulnerabilidade. Tal fato pode ser agravado pelas mudanças fisiológicas do envelhecimento, como perda da visão, equilíbrio, mobilidade reduzida, entre outros (MICHELETTO, 2011). De acordo com Freire Junior et al. (2013), as cidades brasileiras nem sempre são acessíveis aos seus habitantes. As ruas, calçadas, praças, estabelecimentos públicos e comerciais são projetados para pessoas que não apresentam nenhuma dificuldade em locomoção e limitação funcional. Essa condição dificulta a acessibilidade das pessoas idosas e as levam a ficar confinadas em suas casas, acabando por excluí-las das atividades na sociedade.

As queixas relacionadas à acessibilidade não se restringem aos grandes centros urbanos, com maior número de carros e trânsito intenso. Em cidades de médio e pequeno porte também 
é possível perceber muitos problemas de acessibilidade e locomoção para pessoas mais velhas. É o caso do município de Viçosa, Minas Gerais, que possui uma população de idosos de $17 \%$ (CRUZ, 2014). Mafra, Silva e Fontes (2018) retrataram estas dificuldades, apresentando as queixas que a população idosa traziam sobre mobilidade urbana e transporte público dentro de tal município. Vale ressaltar que Viçosa também é conhecida por ser uma cidade universitária, por abrigar uma grande instituição federal de ensino, pesquisa e extensão e por possuir também importantes faculdades particulares e colégios.

Diante da necessidade de entender a relação entre o processo de envelhecimento, as dificuldades de acessibilidade e as possíveis soluções, o presente estudo objetivou descrever a percepção das pessoas idosas sobre a acessibilidade no município de Viçosa-MG, almejando, com isto, subsidiar ações de melhoria para garantir a qualidade de vida dos idosos e sua independência funcional.

\section{MATERIAIS E MÉTODOS}

Trata-se de uma pesquisa de natureza qualitativa e de caráter descritivo. De acordo com Godoy (1995), a pesquisa qualitativa permite a percepção do fenômeno social a ser estudado, pois considera todos os dados coletados fundamentais para a descrição dos fatos. Deste modo, o pesquisador tende a observar tudo à volta do seu grupo de amostra. Gil (2008) pontua, também, que a pesquisa descritiva visa estudar as características de um determinado grupo.

O estudo foi realizado no Município de Viçosa, Minas Gerais, localizado na Zona da Mata Mineira. O referido município pode ser denominado "cidade envelhecida", já que $17 \%$ de sua população é constituída por pessoas idosas (CRUZ, 2014). A proporção de pessoas idosas em Viçosa é superior à média nacional uma vez que, segundo o último censo demográfico, é de 13\% (IBGE, 2018).

Participaram do presente estudo 16 idosos integrantes do Programa Municipal da Terceira Idade (PMTI). O PMTI é um projeto em parceria com a Universidade Federal de Viçosa - MG (UFV), criado no ano de 1997, tendo como objetivo a promoção de qualidade de vida para as pessoas idosas viçosenses. (MAFRA, SILVA e FONTES, 2018)

A coleta dos dados foi realizada por meio da técnica brainstorming. Segundo Alves, Campos e Neves (2007), a técnica foi criada por Alex Osborn, em 1953, cuja tradução significa 
“tempestade de ideias". Tais autores enfatizaram que este método é muito utilizado em diversas áreas de pesquisa devido à sua simplicidade. Para Nóbrega, Neto e Santos (1997), a técnica de brainstorming tem como objetivo coletar ideias de forma coletiva, sem críticas ou julgamentos. Com isso, a escolha pela técnica também se justifica pelo fato de os participantes deste estudo possuírem baixo nível de escolaridade.

Para a aplicação da técnica e a coleta de dados foi questionado aos participantes sobre "quais eram as dificuldades de acessibilidade no município de Viçosa, e quais ações deveriam ser realizadas para solucionar tal problemática”.

Como recomendado por Alves, Campos e Neves (2007), o estudo seguiu todas as etapas da técnica de brainstorming descritas por Baxter (2003) apud Alves, Campos e Neves (2007), em que a primeira delas consistia na fase de orientação, na qual o pesquisador orientava os participantes, lhes apresentando o problema. Em um segundo momento, denominado preparação, o coordenador determinou um tempo para que os participantes da pesquisa explicitassem suas ideias, que foram anotadas pelo relator. Para que os questionamentos não se perdessem em meio ao diálogo, optou-se por utilizar quatro relatores nesta pesquisa.

$\mathrm{Na}$ terceira fase da técnica procedeu-se à análise. Os participantes tiveram um tempo, menor do que a fase anterior, para agrupar as ideias já propostas. Em seguida, iniciou-se a fase de ideação, onde foram escolhidas as ideias mais relevantes. Não houve a necessidade da fase de incubação, já que as informações coletadas no primeiro momento foram satisfatórias. Por fim, ocorreu a síntese e avaliação, que consistiu em um tempo para que os participantes relatassem soluções, confrontando os problemas enfatizados no primeiro momento da pesquisa.

Após a aplicação da técnica foram analisadas as ideias dos quatros relatores. Nesse ínterim, houve o cuidado de eliminar os questionamentos similares que continham as mesmas queixas ou soluções.

A pesquisa obedeceu aos preceitos da ética científica vigentes, conforme resolução nº66/2012 do Conselho Nacional de Saúde, e foi aprovada pelo Comitê de Ética e Pesquisa com Seres Humanos, da Universidade Federal de Viçosa, de acordo com o parecer 1.408.476. Foram garantidos aos participantes o anonimato, o respeito, o sigilo das informações e a possibilidade de desistir de participar da pesquisa a qualquer momento. Os participantes assinaram o Termo de Consentimento Livre e Esclarecido (TCLE). 


\section{RESULTADOS E DISCUSSÃO}

A pesquisa foi realizada com 16 idosos, com média de idade de 68 anos. A maioria do sexo feminino (85\%). Todos os idosos residiam em Viçosa - MG, portanto, vivenciavam diariamente os problemas relacionados à acessibilidade do município. Dentro do Programa Municipal da Terceira Idade (PMTI), estes idosos eram participantes da oficina “A voz do idoso em Viçosa".

Com relação ao estado civil, $45 \%$ disseram ser casados; $27,5 \%$ viúvos; e os outros $27,5 \%$ divorciados ou separados. Ao serem questionados sobre alfabetização, a maioria, (85\%) respondeu que sabia ler e escrever; 7,5\% não sabiam; e os demais 7,5\% estavam em processo de aprendizagem. Segundo Almeida et al. (2018), o baixo nível de escolaridade resulta em dificuldades para conhecer e buscar seus direitos, impossibilitando aos idosos exigir o que lhes é assegurado por lei, fortalecendo o sentimento de exclusão na sociedade. Quanto à renda, 92\% dos idosos afirmaram que recebiam aposentadoria, sendo o valor do benefício de um salário mínimo.

Por meio da técnica aplicada nesta pesquisa, os idosos relataram diversos problemas relacionados com a acessibilidade, os quais constituíam barreiras quanto à participação de atividades na comunidade. Alguns idosos citaram que certos problemas de acessibilidade estavam relacionados à infraestrutura do município, como buracos e obstáculos nas calçadas e faixas de pedestres apagadas. Muitos idosos relacionaram as péssimas condições físicas da cidade com a falta de interesse do Poder Público. O transporte público também foi mencionado como barreira urbana pelos idosos; dentre os principais pontos, foram citados o preconceito de forma geral, a falta de informações sobre horários de ônibus e indisponibilidade da carteirinha do idoso. Além disso, relatos de quedas e acidentes durante o deslocamento pela cidade foram enfatizados durante a conversa com os idosos.

Os entraves citados pelos idosos perpassaram por problemas ligados ao transporte, à infraestrutura, à administração pública, à falta de informação, a acidentes e, por fim, ao preconceito sofrido diariamente por ser idoso. Com isso, a partir das falas dos participantes foi possível elaborar um esquema que ilustrasse os principais entraves expostos pelos mesmos. 
Figura 1: Entraves para a acessibilidade de pessoas idosas em Viçosa - MG.

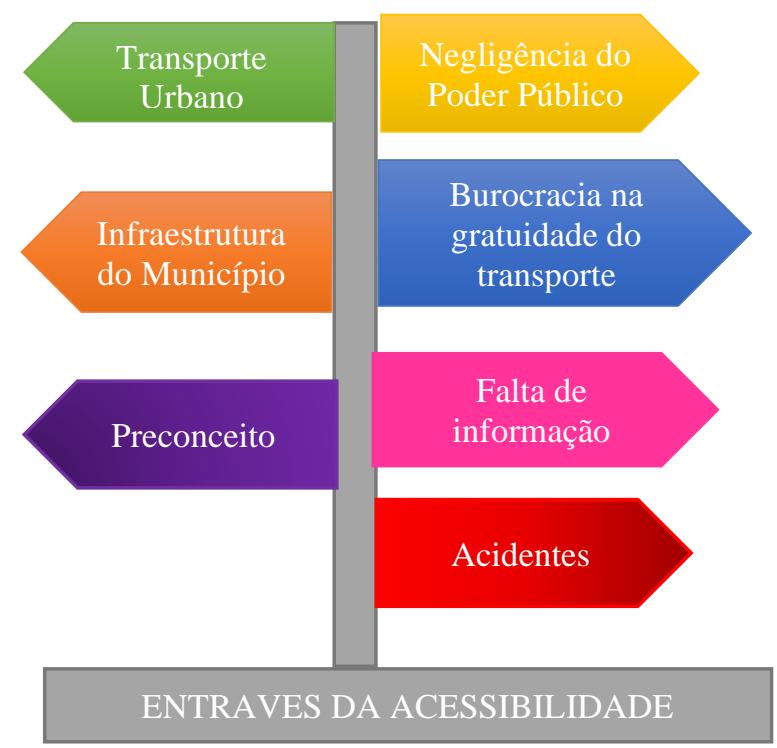

Fonte: Dados da pesquisa, 2019.

Os estudos de Freire Junior et al. (2013), Micheletto (2011), Góes et al. (2008), Santos et al. (2017) e Mafra, Silva e Fontes (2018) também evidenciaram os problemas apresentados na Figura 1. Todo este contexto permite inferir que essas dificuldades na acessibilidade não são restritas a Viçosa, mas sim que são enfrentadas por idosos de outros municípios.

A mobilidade urbana vem das interações entre os meios de transporte, as modalidades e a infraestrutura, cujo objetivo é promover a movimentação harmônica das pessoas pelas cidades. Entretanto, questões como crescimento populacional e das cidades, bem como falta de políticas de planejamento e gestão urbana podem comprometer esta interação (BARRETO; PORTO, 2016).

Os idosos viçosenses relataram dificuldades de percorrer as ruas devido às péssimas condições das calçadas e dos calçamentos, destacando, ainda, a ausência das faixas de pedestres. Tal situação pode ser evidenciada nas falas a seguir.

\footnotetext{
"Tenho dificuldades para andar nas ruas, o calçamento é péssimo" (Idoso 1).

"No bairro João Braz, a faixa de pedestre apagou" (Idoso 2).
} 
"Na rua Coimbra, a boca de lobo está aberta" (Idoso 3).

Os dados desta pesquisa corroboram o que Fonseca et al. (2018) verificaram em seu estudo, destacando as pinturas apagadas das faixas de pedestre, além da dificuldade em caminhar pelas calçadas, pois quando não estavam em condições precárias, os bares as utilizavam para colocar mesas e os estudantes paravam para "bater papo", impedindo a passagem. Barreto e Porto (2016) também identificaram problemas na infraestrutura da cidade de Montes Claros - MG em relação à acessibilidade, entre eles, a falta de rampas em prédios públicos, pontos de ônibus sem cobertura, bancos e calçadas sem padronização e com obstáculos.

Os idosos viçosenses apontaram, ainda, o trânsito como um problema que dificulta a acessibilidade. Segundo eles, o número de veículos e a falta de organização do tráfego acaba sendo uma barreira à acessibilidade. Esta questão pode ser observada nas falas dos idosos 4 e 5.

“O trânsito é muito intenso" (Idoso 4).

“Já cai na rua, pois o trânsito está cada vez pior, e as calçadas são muito ruins, não dá pra andar" (Idoso 5).

Portugal e Loyola (2014) enfatizaram que a queda é vista como um problema para os idosos, e dentre os fatores que contribuem para tal acontecimento podem ser mencionadas as calçadas desniveladas, os obstáculos nas ruas, a falta de sinalização, entre outras condições também verificadas no município investigado neste estudo.

Um problema-destaque abordado pelos idosos desta pesquisa, refere-se ao transporte público. Muitos afirmaram sofrer com o preconceito e a discriminação dos trocadores de ônibus frente às suas limitações. Essas queixas podem ser notadas nas falas dos idosos 6 e 7.

"O trocador me chamou de velho folgado" (Idoso 6).

"Existe a carteirinha para o idoso, mas existe também limite de lugar dentro do ônibus" (Idoso 7).

As falas explicitaram claramente o preconceito sofrido pelos idosos, sendo possível perceber o sentido pejorativo que os profissionais do transporte urbano atribuíram aos usuários 
idosos. Fonseca et al. (2018) citaram o Estatuto do Idoso, o qual prevê no transporte intermunicipal 2 vagas gratuitas para os idosos que comprovarem renda inferior a dois salários mínimos. Caso exceda o número de vagas gratuitas no transporte, os demais têm direito a desconto de 50\% no valor total da passagem. De acordo com Góes et al. (2008), a Constituição Federal de 1988 também abrange a questão da gratuidade no transporte público para as pessoas idosas.

Silva, Mafra e Fontes (2017) apresentaram resultados semelhantes, pois os idosos reclamavam das dificuldades em utilizar o transporte público, ressaltando a falta de respeito com os acentos preferenciais, muitas vezes ocupados por pessoas mais jovens, assim como a falta de respeito dos motoristas rejeitando o sinal de parada dos idosos e arrancando o veículo com estas pessoas ainda de pé.

Os idosos apontaram ainda, dificuldades durante a utilização do transporte público em Viçosa - MG, dentre elas, a falta de informação e negligência para fazer a carteirinha do idoso, e a plataforma inadequada de acesso ao veículo, o que dificulta as entradas e saídas do mesmo. As falas abaixo ilustraram esse problema:

"A lotação fica cheia e tenho dificuldades em subir e descer do ônibus" (Idoso 8).

"O degrau do ônibus é muito alto" (Idoso 9).

"Não consigo fazer a minha carteirinha do idoso, e ninguém sabe me informar o porquê" (Idoso 10).

"Não sei os horários dos ônibus e não tenho informações sobre como usar a carteirinha do idoso" (Idoso 11).

Nota-se que, assim como na pesquisa de Góes et al. (2008) que, em relação ao uso do transporte público pelos idosos, existem situações de negligência, desrespeito, discriminação, o que acaba por inibir os idosos de usufruírem de um direito que lhes é garantido por lei. De acordo com Santos et al. (2017), os meios de transporte são necessários para que idosos tenham acesso a serviços de saúde, atividades sociais e lazer. Sendo assim, as barreiras físicas relacionadas à acessibilidade dificultam a mobilidade destes indivíduos, que são considerados uma parcela significativa nas cidades (BENDER, DELBONI, AEROSE, 2015).

Os idosos do PMTI também apresentaram possíveis soluções para os problemas 
encontrados associados à acessibilidade urbana. Na percepção deles, as empresas de ônibus deveriam oferecer treinamento aos colaboradores e motoristas para que, assim, pudessem adotar boas condutas e atitudes com os usuários do transporte público. A fala do idoso 12 demonstra esta necessidade ou sugestão:

\footnotetext{
"Os cobradores e motoristas tem que receber treinamento para lidar com o público" (Idoso 12).
}

A gratuidade é um direito da pessoa idosa, por isso, este cidadão deve ser respeitado como qualquer outro usuário. Segundo Góes et al. (2008), as empresas de transporte deveriam promover campanhas educativas aos seus funcionários. Barreto e Porto (2016) sugeriram a criação de meios alternativos de transportes, como trens, metros e bicicletas, assim, pode-se reduzir o número de veículos nas vias de circulação, permitindo maior segurança e uma mobilidade urbana mais eficiente.

Outra alternativa apontada pelos idosos relaciona-se ao Poder Público Municipal. Os idosos reconheceram o papel da esfera administrativa para solucionar os problemas da infraestrutura da cidade, que acabam por limitar a acessibilidade.

“Cobrar do prefeito e vereadores mais atenção com relação à infraestrutura da cidade" (Idoso 13).

Segundo Barreto e Porto (2016), as cidades com população acima de 20 mil habitantes devem contar com um Plano Diretor, que consiste em orientações de políticas relacionadas ao desenvolvimento das cidades, planejamento e gestão urbana. Estes autores enfatizaram que as legislações destinadas a assegurar um acesso seguro e autônomo para todos os habitantes da cidade de Montes Claros - MG não são contempladas de forma correta, pois, na maioria das vezes, não contam com a participação da sociedade durante a sua elaboração, apresentando apenas aspectos técnicos e atendendo, por isso, a preocupações de grupos econômicos.

A cidade de Viçosa conta com o Plano Diretor, de acordo com a Lei n ${ }^{\circ} 1.383 / 2000$, em seu capítulo VII, o qual se refere à estruturação das vias e mobilidade urbana. O art. 138, que prevê acessibilidade universal, pauta condições para a utilização de tudo o que envolve o sistema de mobilidade para pessoas com deficiência e mobilidade reduzida de forma segura e 
independente.

De acordo com os problemas apontados neste estudo pelos idosos, pode-se verificar que o Plano Diretor de Viçosa através da lei $n^{\circ} 1.383 / 2000$, apesar de prever a acessibilidade universal, não garante este direito não só aos idosos, mas a toda população viçosense.

Micheletto (2011) destacou em seu trabalho o programa criado pela prefeitura de São Paulo, cujo objetivo foi auxiliar na manutenção e recuperação das calçadas, denominado "Passeio Livre". Sua função foi "contribuir para melhorar a paisagem urbana, a acessibilidade, o resgate do passeio público pela calçada e a socialização dos espaços públicos" (MICHELETTO, 2011, p. 8). Em relação às deficiências encontradas nos transportes públicos, este autor também menciona duas medidas adotadas pela cidade de São Paulo, que foi a elevação das calçadas onde há plataformas para $28 \mathrm{~cm}$, diminuindo o degrau que dá acesso ao ônibus, e a construção de rampas, reduzindo o risco de quedas na população idosa.

Outro exemplo ocorreu na cidade de Curitiba - PR, onde a prefeitura, visando minimizar os problemas relacionados aos acidentes nas calçadas da cidade, criou, em 2014, o Plano estratégico das calçadas, reformando e recuperando um item de mobilidade extremamente importante para a sua população. Além deste projeto, outras ruas e avenidas foram planejadas com faixas livres, sem obstáculos e desníveis. O objetivo era atender às pessoas com mobilidade reduzida, como os idosos, deficientes e mães com carrinho de bebê (PORTUGAL; LOYOLA, 2014).

Acredita-se que iniciativas similares às que foram adotadas em São Paulo e Curitiba poderiam ajudar a reduzir e ou, ao menos, a minimizar os entraves da acessibilidade no município de Viçosa - MG.

A mobilidade não está associada apenas ao trânsito, veículos, andar a pé, e, sim, representa o conjunto de infraestrutura de serviços, informações e instituições. Deste modo, é necessária a locomoção das pessoas de forma segura e sustentável. Porém, é visível que tais condições não são totalmente oferecidas, principalmente para as pessoas idosas, apesar de inúmeras leis que priorizam a acessibilidade para esta população. Por esse motivo, a limitação no deslocamento para estes indivíduos gera consequências que vão deste a falta de interação e participação na sociedade até acidentes que resultam em mobilidade ou óbito das pessoas idosas. 


\section{CONCLUSÃO}

Este estudo permitiu concluir que, em Viçosa - MG, a acessibilidade urbana constitui um entrave que afeta a locomoção das pessoas idosas. Na percepção dos idosos viçosenses, as principais dificuldades advindas da acessibilidade eram a deficiência na infraestrutura e no transporte público, a negligência do poder público, o preconceito por parte dos funcionários dos ônibus e o risco de quedas. Os problemas ligados à acessibilidade não são restritos à cidade de Viçosa, os mesmos são encontrados em grandes centros urbanos.

Além dos problemas de acessibilidade, os idosos propuseram possíveis soluções, visando amenizar tais entraves, como treinamento e cursos de capacitação dos motoristas e cobradores de ônibus, fiscalização dos serviços de acessibilidade, participação mais ativa do poder público municipal, buscando melhorias na infraestrutura da cidade. Em algumas cidades pode-se identificar ações governamentais, a fim de atender a toda população, dando atenção principalmente às pessoas idosas.

Os impasses da acessibilidade urbana em relação à população idosa criam condições que acabam excluindo estes indivíduos de uma participação mais ativa e independente nas cidades brasileiras. Portanto, é importante reconhecer que estas pessoas necessitam de uma maior atenção, visto que o envelhecimento traz consigo limitações funcionais que, juntamente com as barreiras arquitetônicas, impactam na vida dos idosos, causando, em alguns casos, o isolamento social.

\section{REFERÊNCIAS}

ALMEIDA, A. V.; MAFRA, S. C. T.; SILVA, E. P.; HUDSON, S. B. M. Características Sociodemográficas. In: MAFRA, S. C. T.; SILVA, E. P., FONTES, A. F. R. (Org.). ComunIDADE, identIDADE, plasticIDADE, nada disso interessa-nos...Interessa-nos envelhecer com DignIDADE. 1ed. Visconde de Rio Branco: Suprema, 2018, v. 1, p. 19-28.

ALVES, H. A.; CAMPOS, F. F. C.; NEVES, A. M. M. Aplicação da técnica criativa Brainstorming Clássico na geração de alternativas na criação de games. In: SIMPÓSIO BRASILEIRO DE JOGOS PARA COMPUTADOR E ENTRETENIMENTO DIGITAL, 6 ., 2007, Porto Alegre. Anais [...] 2007. Disponível em: http://www.sbgames.org/papers/sbgames07/artanddesign/full/ad2.pdf. Acesso em: 07 jul. 2019. 
BARRETO, J. B.; PORTO, C. H. de. Q. Mobilidade urbana, acessibilidade e seguridade no transito para população idosa em Montes Claros - MG. Revista Cerrados Montes Claros, v.14, n.2, p. 230-249, jul/dez-2016. Disponível em:

https://dialnet.unirioja.es/servlet/articulo?codigo=5761485. Acesso em: 07 jul. 2019.

BENDER, M. S; DELBONI, M. C; AEROSE, S. V. C. O idoso, pessoas com mobilidade reduzida e a questão da acessibilidade. In: SICS: DESAFIOS CONTEMPORÂNEOS:

TENSÕES ENTRE O GLOBAL E O LOCAL, 4., 2015, Belo Horizonte/MG. Anais [...]. Tema: Desafios contemporâneos: tensões entre o global e

o local, 2015. Disponível em: http://portaleventosacademicos.pucminas.br/index.php/simposi oics/ivsics/paper/download/487/145. Acesso em: 8 ago. 2019.

BRASIL. Constituição (1988). Constituição da República Federativa do Brasil.

Promulgada em 5 de outubro de 1988. Brasília, DF, 1988. Disponível em:

http://www.planalto.gov.br/ccivil_03/constituicao/constituicao.htm. Acesso em: 07 jul. 2019.

CRUZ, T. A. (Coord). Retrato Social de Viçosa. 5 ed. Viçosa, MG: CENSUS, 2014, 91p. 2014. Disponível em: https://docplayer.com.br/7597147-Retrato-social-de-vicosa.html. Acesso em: 09 ago. 2019.

FONSECA, E. S.; et al. Os desafios de se envelhecer. In: MAFRA, S. C. T.; SILVA, E. P., FONTES, A. F. R. (Org.). ComunIDADE, identIDADE, plasticIDADE, nada disso interessa-nos...Interessa-nos envelhecer com DignIDADE. 1ed. Visconde de Rio Branco: Suprema, 2018, v. 1, p. 29-48.

FREIRE JUNIOR, R. C; et al. Estudo da acessibilidade de idosos ao centro da cidade de Caratinga, MG. Revista Bras. Geriatria. Gerontologia, Rio de Janeiro, v. 16, n. 3, p. 541558, 2013. Disponível em: http://www.scielo.br/scielo.php?pid=S180998232013000300012\&script=sci_abstract\&tlng=pt. Acesso em: 6 jul. 2019.

GIL, A. C. Todas as técnicas de pesquisa social. 6.ed. São Paulo: Atlas, 2008. Disponível em: https://ayanrafael.files.wordpress.com/2011/08/gil-a-c-mc3a9todos-e-tc3a9cnicas-depesquisa-social.pdf. Acesso em: 7 jul. 2019.

GODOY, A. S. Pesquisa qualitativa: tipos fundamentais. Revista de Administração de Empresas, v. 35, n. 3, p. 20-29, 1995. Disponível em:

http://www.spell.org.br/documentos/ver/12736/pesquisa-qualitativa--tipos-fundamentais. Acesso em: 6 jul. 2019.

GÓES, A. A. F.;et al. Percepção dos Idosos sobre o Transporte Público no Distrito Federal. Pesquisas e Práticas, São João Del-Rei, v. 3, n. 1, p. 58-65 2008. Disponível em: https://repositorio.ucb.br/jspui/bitstream/123456789/7619/1/Percep\%C3\%A7\%C3\%A3o_idos os_Transporte\%20pubico.pdf. Acesso em: 8 jul. 2019.

INSTITUTO BRASILEIRO DE GEOGRAFIA ESTATÍSTICA. IBGE. INSTITUTO BRASILEIRO DE GEOGRAFIA ESTATÍSTICA. IBGE. Projeções da população. 2018. Disponível em: https://www.ibge.gov.br/estatisticas/sociais/populacao/9109-projecao-da- 
populacao.html?=\&t=conceitos-e-metodos. Acesso em: 20 ago. 2020.

MAFRA, S. C. T.; SILVA, E. P.; FONTES, A. F. R. ComunIDADE, identIDADE, plasticIDADE, nada disso interessa-nos... Interessa-nos envelhecer com dignIDADE. Vinconde do Rio Branco - MG: Suprema. 2018.

MICHELETTO, T. M. G. P. O risco do idoso pedestre nas vias urbanas. Companhia de Engelharia de Tráfego de São Paulo - NT 219. 2011. Disponível em: http://www.cetsp.com.br/media/96549/nt219.pdf. Acesso em: 8 jul. 2019.

MIRANDA, G. M. D.; MENDES, A. da. C. G.; SILVA, A. L. A. da. O envelhecimento populacional brasileiro: desafios e consequências sociais atuais e futuras. Rev. Bras. Geriatr. Gerontol., Rio de Janeiro, 2016. v.19. n.3. p. 507-519. Disponível em: http://www.scielo.br/scielo.php?pid=S1809-

98232016000300507\&script=sci_arttext\&tlng=pt. Acesso em: 7 jul. 2019.

NÓBREGA, M. de. M.; NETO, D. L.; SANTOS, S. R. de. Uso da técnica de brainstorming para tomada de decisões na equipe de enfermagem de saúde pública. R. Bras. Enferm., Brasília, v. 50, n. 2, p. 247-256, abr./jun. 1997. Disponível em:

http://www.scielo.br/pdf/reben/v50n2/v50n2a09.pdf. Acesso em: 7 jul. 2019.

ORGANIZAÇÃO MUNDIAL DA SAÚDE - OMS. Relatório Mundial de envelhecimento e saúde. 2005. Disponível em: https://sbgg.org.br/wp-content/uploads/2015/10/OMSENVELHECIMENTO-2015-port.pdf. Acesso em: 6 jul. 2019.

PIMENTEL, R. M.; SCHEICHER, M. E. Comparação do risco de quedas em idosos sedentários e ativos por meio da Escala de Berg. Fisioterapia e Pesquisa, São Paulo, v.16, n.1, p.6-10, jan./mar. 2009. Disponível em: http://www.scielo.br/pdf/fp/v16n1/02.pdf. Acesso em: 8 jul. 2019.

PORTUGAL, M. E. G; LOYOLA, E. A T. Mobilidade urbana adequada para os idosos: uma importante questão de saúde coletiva. Revista gestão \& saúde

(Curitiba), v. 10, p. 2634, 2014. Disponível em: http://www.herrero.com.br/files/revista/file2 237968b4539a265033105c31a84538b.pdf. Acesso em: 8 jul. 2019.

SANTOS, M. D.; et al. Falta de acessibilidade no transporte público e inadequação de calçadas: efeitos na participação social de pessoas idosas com limitações funcionais. Rev. Bras. Geriatr. Gerontol., Rio de Janeiro, 2017; 20(2): 161-174. Disponível em: http://www.scielo.br/pdf/rbgg/v20n2/pt_1809-9823-rbgg-20-02-00161.pdf. Acesso em: 6 jul. 2019.

SILVA, E. P.; MAFRA, S. C. T.; FONTES, A. F. R. A pessoa idosa e o "conhecimento prático" e sua práxis na efetividade de direitos e deveres. In: I SEMINÁRIO NACIONAL: Família e Políticas Sociais no Brasil - UFV. 2017. Disponível em: http://www.ppged.ufv.br/seminariofamiliapoliticassociais/wp-content/uploads/A-pessoaidosa-e-o-conhecimento-pr\%C3\%A1 tico-e-sua-praxis-na-efetividade-de-direitos-edeveres.pdf. Acesso em: 6 jul. 2019. 
SILVA, E. P; et al. Envelhecer no olhar da pessoa idosa: uma análise a partir do software IRAMUTEQ. Braz. J. of Develop., Curitiba, v. 4, n. 6, p. 3386-3400, out./dez. 2018.

Disponível em: http://www.brjd.com.br/index.php/BRJD/article/view/332. Acesso em: 7 jul. 2019.

VIÇOSA (MG). Câmara Municipal de Viçosa. Lei no 1.383/2000. Institui o Plano Diretor do Município de Viçosa - MG. 2000. Disponível em: https://www.vicosa.mg.leg.br/portlets-edestaques/plano-diretor-1/projeto-de-lei/view. Acesso em: 7 jul. 2019.

\section{Declaração de Interesse}

Os autores declaram não haver nenhum conflito de interesse

\section{Financiamento}

Financiamento próprio

\section{Colaboração entre autores}

SOARES, B. P. Concebeu o estudo, participou do planejamento da pesquisa, realizou a coleta e analisou os dados, responsável pela criação das tabelas e resultados, bem como escreveu o manuscrito. MAFRA, S. C. T. Colaborou com a coleta dos dados, assim como contribuiu com partes significativas para a pesquisa. SILVA, E. P. da. Participou do planejamento do estudo, orientou todas as etapas da pesquisa, contribuiu com o desenho e interpretação dos dados, bem como a revisão do texto e adição de partes significativas. 